\title{
Research on the Method of Comparing the System Layer to Foil Reservoir
}

\author{
Fan Yanqiong \\ The Fifth Production Plant of Daqing Oil Field Limited-liability Company, Daqing,163513, China \\ e-mail: fyanqiong@petrolchina.com.cn
}

Keywords: Foil reservoir; Compare the system layer; Well-log and seismic data

\begin{abstract}
Comparing the system layer is the key and foundation of reservoir research, but The F oil reservoir belongs to the diversion plain and the leading edge of the reservoir, and it is not suitable to use thick contrast method. At the same time, well network density is very small, and the comparison of well logging curve is not obvious. Therefore, it is very difficult to compare the conventional oil reservoirs with the core and well logging curves in the area of the district. Therefore, it is necessary to find a suitable method to improve the accuracy of the research, which is suitable for the support of the oil layer, and lay a solid foundation for the follow-up study.
\end{abstract}

\section{Introduction}

Reserve in recent years, in order to look for oilfield development potential, factory conducted F oil reservoir evaluation. By well logging, mud logging, coring and testing, data analysis, think $\mathrm{F}$ oil layer has a certain oil and gas shows and capacity, is an important reserves potential. At present, the $F$ reservoir research is still in its infancy, and reservoir is the key to reservoir study of comparison and basis, but within $F$ reservoir belongs to shunt plain and front facies[1][2], unfavorable use thickness contrast method, and well spacing density is small, and the characteristics of logging curve comparison is not obvious. As a result, the F reservoir only with the aid of coring Wells and well logging curve to conventional reservoir comparison[3], difficulty is very big, easy to layer, unable to get ideal results, restricted reservoir follow-up studies. So, it is necessary to find out suitable for F to contrast series oil layer method, in order to improve precision of the contrast and to lay a solid foundation for the subsequent reservoir research.

\section{Establish Vertical Comparison Standard}

F reservoir in the study area well pattern density is small, and the objective layer within the scope of all kinds of well logging curve in the aspect of classified reservoir boundary and no obvious sign of traceability, reservoir classification and correlation difficulty particularly large, lead to the logging curve classification comparison of conventional methods for the classification and correlation of results precision is high enough. By contour map formation thickness and for even well logging curve profile of previously only preliminary reservoir using well logging curve comparison results is analyzed, found that some change of strata thickness is bigger, especially FI oil layer, formation thickness changes between $90 \mathrm{~m}$ to $135 \mathrm{~m}$, average in the $110 \mathrm{~m}$, the thickness of strata thickness change is particularly big, the stratigraphic thickness of about $95 \mathrm{~m}$ of Wells and well distribution of the thickness of about $120 \mathrm{~m}$ more. Another small group of internal oil layer lines between no reliable evidence is whether it is accurate. Because of $F$ reservoir classification and correlation of the above problems, so need to explore new ways to solve, that is to build a vertical comparison standard (can the district or looking for bigger range can trace contrast), and then form a new comparative approach. This project is mainly considered by integrating well data and seismic information to solve this problem[3][4].

Layer Classification and Correlation Standards. (1)In F oil layer top boundary: acoustic time, gamma curve, such as mutation characteristics is very obvious, formed in natural gamma ray and lateral depth curve obvious "high point" (Fig. 1), the whole work area can be a very good track.

(2)In F oil layer at the bottom: although the precise location is difficult to determine, but the 
acoustic time difference, the resistivity curve near the boundary has the characteristics of "oscillation frequency is larger.

(3)FI oil layer bottom: characteristics of well logging curve is not obvious, but the corresponding seismic horizon FII trough, can better track.

(4)FII oil layer bottom: log layering characteristic is not obvious, but the corresponding seismic horizon FIII troughs lower position, poor continuity, but local can better tracking.

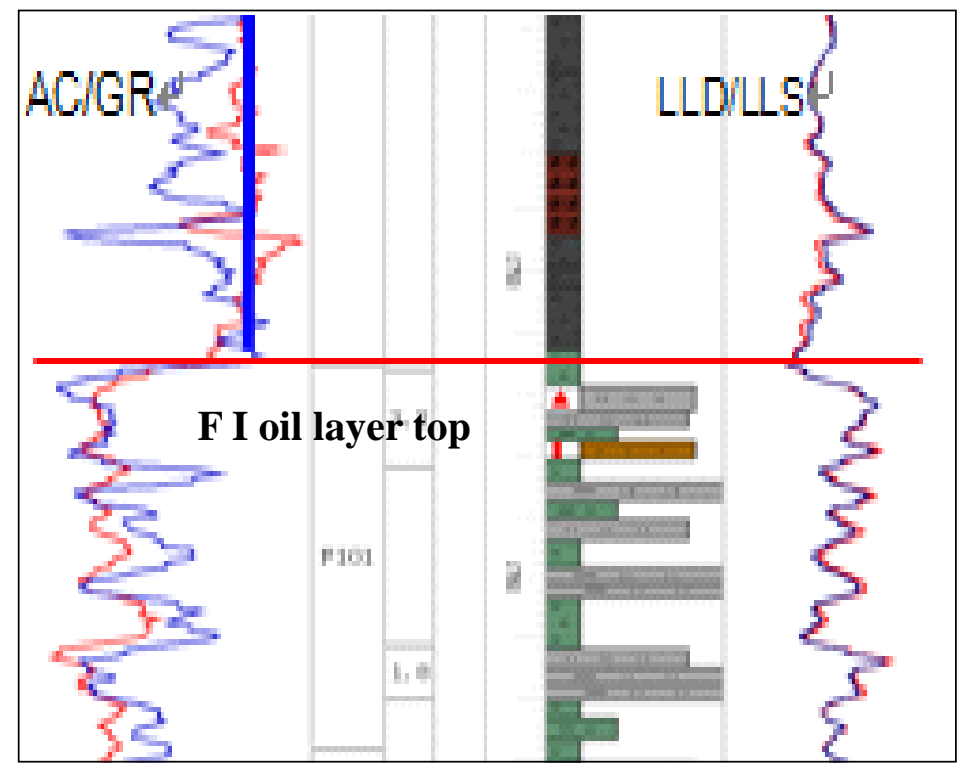

Fig.1 F oil layer top boundary well logging curve feature

Sandstone Group Classification and Correlation Standards. FI at the Bottom of the Reservoir Sandstone in Group. According to the characteristic curve FI reservoir sandstone group as a whole for a complete cycle, according to core analysis, from top to bottom, composed of siltstone, sandstone argillaceous siltstone, silty mudstone, mudstone, lithological change obviously, sand body development, in the FI at the bottom of the reservoir sandstone on group, stable distribution gray-green mudstone layer, the layer common deposit taking FI reservoir group sandstone on bottom part of the interface, stable deposition, the district can track continuously contrast, usually with a thick layer of $0.5-1 \mathrm{~m}$. Top acoustic time difference curve in high performance for jet lag, characterized by high value, GR curve for low resistivity curve, FI sandstone at the bottom of the reservoir sandstone on group is divided into parts group and the comparison of small layer boundary layer (Fig.2) standard.

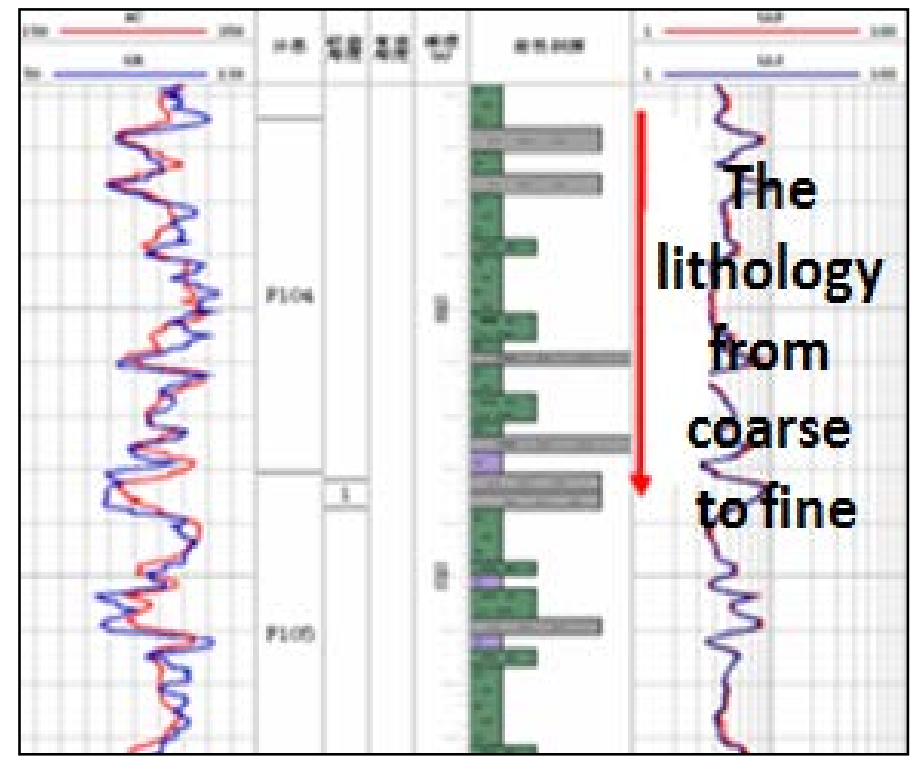

Fig.2 FI reservoir sandstone in the bottom interface 
FII at the Bottom of the Reservoir Sandstone on the Group. According to the characteristic curve FII reservoir sandstone as a whole for a complete cycle, acoustic time difference curve and the GR curve ups and downs is bigger, the peak shape, in FII reservoir group on sandstone at the bottom of the acoustic time curve is characterized by high time top, characterized by high value, GR curve for low resistivity curve. According to core analysis, sand body development, from top to bottom, from siltstone, argillaceous siltstone, sandstone and mudstone, lithology changes significantly, at the end of FII reservoir group on sandstone, stable distribution of purple mudstone layer, the layer is generally save FII reservoir group sandstone on bottom part of the interface, stable deposition, the district can track continuously contrast, usually with a thick layer of about $1 \mathrm{~m}$.

\section{Well Shock Combined with Contrast System Layer Method}

The shaft vibration combined with contrast system layer method is as follows.

(1) Reservoir compared with conventional methods, namely, to establish standard well skeleton section, the logging curve to small layer by the reservoir group step by step close comparison. On the basis of standard skeleton section closed well, all of the well logging curve profile is compared.

(2) And then to make synthetic seismogram calibration and single well track explaining seismic horizon[5], calibration and tracking wells in the process of mutual authentication, to mark layer reservoir group in the study area well unified.

(3) Logo well shock after unification, based on the strata subdivision method of proportion of sandstone group level isochronous stratigraphic framework, is converted to depth domain when deep sandstone set boundaries, the reservoir with well logging curve comparison results compare to each other, to adjust error too large sandstone set boundaries[6], make the sandstone group boundary well unified.

(4) Sandstone group boundary well shock after unification, based on the strata subdivision method to establish a small level of proportion of isochronous stratigraphic framework, is converted to depth domain in deep layer boundary, with the reservoir logging curve comparison results compare to each other, adjust error is too large of small layer boundary, make small shock layer boundary well unified.

\section{Conclusion}

Through well and properly set up accurate corresponding relationship between well logging and seismic; through the analysis of the seismic horizon traceability to establish reservoir earthquake standards, and track the seismic horizon; the high vertical resolution of logging curve and the characteristics of the seismic horizon can track continuously, realize high precision reservoir contrast.

\section{References}

[1] Li Yanping, shu-min Chen, etc. Wells of Daqing changyuan and east three or four helped shallow water lake delta system in fuyang reservoir sedimentary characteristics. Daqing petroleum geology and development. 24 (5) : 13 to 16

[2] wang, operation should be long, etc. The sand around the period of dongying sag characteristic of sedimentary environment and sedimentary model. Journal of deposition. 2012, 30 (2) : 274-281

[3] cheng-wen lee. Main development and new progress in geophysical prospecting method [J]. Journal of chengdu university of technology. 2003

[4] liu zhen. The reservoir seismic stratigraphy [M]. Geological press, Beijing. 1997

[5] land-based meng. Seismic prospecting principle. China university of petroleum press. 2006

[6] cao three degrees. The reservoir prediction using logging constrained inversion difficulties and 
solutions [J]. Journal of Anhui geological. 2004 